\title{
Still “Choosing Our Futures": How Many Apples in the Seed?
}

\section{James G. Neal}

Ralph Waldo Emerson, the American essayist and poet, noted in his Journals ${ }^{1}$ that "sometimes a scream is better than a thesis." Perhaps the authors of the remarkable paper "Choosing Our Futures" were inspired by Emerson's rumination. This 1996 article is a provocation, a call to arms for the academic library community, a challenge to complacency, an insightful and inciteful spur to fundamental change. In the context of extraordinary economic pressures, the early transformation of scholarly communication, new thinking about the role and nature of higher education, rampant technological innovation, rapidly shifting user behaviors and expectations, the authors confront the classic debate on the nature of transformation. Will it be incremental, evolutionary, or revolutionary? They also flirt with the prospect of extinction: that is, will it be terminal, the demise of the academic library, or will it be phyletic, the library surviving by progressing to a new species? Why was the "Choosing Our Futures" essay important in 1996, and why is it still compelling today?

Published nearly twenty years ago, and presented through the lens of the authors' experiences at the University of Arizona, the paper encourages us to think about the multifaceted character of organizational transformation. What do we mean by transform: to change in composition or structure, what we are and what we do? to change in outward form or appearance, how we are viewed and understood? and to change in character or condition, how we do it? The authors are responsive to two cautions. Subjective perceptions are at least as important as the actual facts. And, in the short run, change is always less than expected - but, in the long run, always more than anticipated. Khalil Gibran, the poet and writer, tells us that "progress lies not in enhancing what is, but in advancing toward what will be." ${ }^{2}$ And Thomas Kuhn, in The Structure of Scientific Revolutions, reminds us that "the transition from a paradigm in crisis to a new one from which a new tradition can emerge is far from a cumulative process." 3 This paper captures the essence of these two important concepts.

The basic premise of the paper was that "every assumption, task, activity, relationship, and/or structure needed to be challenged." The authors advance a constancy of purpose, building on Jesse Shera's point that the role of libraries is to "maximize the social utility of graphic records." Even from the perspective of the mid-1990s, they see the shifting and increasingly schizophrenic vision of the academic library. They could not have understood the future impact of such developments as the web, social media, the cloud, mobile technologies, big data, 3-D printing, visualization, and all the rest. But they recognize the importance of legacy, infrastructure, repository, portal, enterprise, and public interest as part of the continuing mandate. Theirs is a clarion appeal for innovation, for new ideas, methods, and products. They call for the systematic application of new knowledge to new resources to produce new goods and new services,

James G. Neal is University Librarian Emeritus at Columbia University; e-mail: jneal@columbia.edu. (C) 2015 James G. Neal, Attribution-NonCommercial (http://creativecommons.org/licenses/by-nc/3.0/) CC BY-NC. 
responsive to the market. They advocate a process of lowering the costs and increasing the benefits of the work, adding value. They encourage new and deliberate thinking about existing challenges and unmet needs, a focus on solutions.

Today, there is a constancy in the trends they observed and the angst they felt, albeit with a different vocabulary and base of experience. They bemoan the aging and ineffective service paradigms, citing the failures of discovery, the expansion in user alternatives, and the need to move the library staff closer to the student and the researcher. They criticize the redundant and inefficient library operations, as well as the inclination to apply new technology to the automation of old workflows. They suggest the mounting open revolution, of open access, open source, open architecture, open design, open linking. They see the polycentrism across the academic library community, of parallel but disconnected development and innovation, of weak professional communication systems and forums. They argue for mutability, for constant change, hybrid structures, and maverick strategies, embracing in the title of the paper the need for multiple and even divergent futures. They presage the user experience and assessment movements. They predict the potential scale and network effects through aggregation and linked data. They embrace the acceleration of collective innovation, the future applications revolution. They champion the entrepreneurial imperative.

There are many "musts" and "radical changes" demanded in this paper: We must steer away from our traditional functions, spaces, and collections, and view ourselves more as educators and knowledge managers. We must stop "organizing library work around things" and "focus on customers and their needs." We must rethink the library organization, reducing bureaucracy and hierarchy, concentrating more on chaos and less on order. We must take a more process-oriented and systematic approach to our work and be more aligned with benchmarking, competition, and opportunity costs. We must reduce our isolation and radicalize our relationships and partnerships on campus and in the wider library, learning, and scholarly communities. We must rethink the allocation of our resources, stopping the incremental investment in traditional and operational areas and starting with the strategic and innovative. We must reduce the class structures in library staffs, as it erodes a shared mission and reduces creativity and productivity. We must redefine the nature and purpose of leadership, accepting the importance of coaching and mentoring, reducing the culture of authority and control, and "living with ambiguity and uncertainty," as leadership must permeate the library organization.

When this paper was published in College E Research Libraries, several commentaries were also included. ${ }^{4}$ Susan Lee (Harvard) takes a research library perspective, arguing that "different pasts" will encourage us to "choose different paths to different futures." She accuses the authors of ignoring the diversity among the research libraries and the continuing relevance of deep paper-based historical, special, distinctive, and global collections. She bemoans the "corporate model" for change, the "technological hype," the "fear-based" demand for "trauma and destruction," and the alarmist characterization of the then library condition. Her strategy is a "long-term reorientation," "not so fast and not so much." Bonnie Juergens (AMIGOS) takes the library service network perspective, contending that "a restructuring of the way academic libraries do business" is essential and that pervasive change in the private sector dictates a similar response in the academic library. She aligns with the message but acknowledges that the "call to arms" is "primarily observational" and not well documented. Networks, she contends, are agents of education and training, the providers of new products and services, consultants, the enablers of interorganizational relationships, supporters of research and development, and leaders of change. Richard Werking (U.S. Naval Academy) takes an historical perspective and applauds the balance of successful "continuity 
and change" we have achieved in academic libraries. He is befuddled by the opinions offered in the paper and troubled by "admonitions" in the absence of "research findings and detailed accounts." He projects a future for academic libraries that sets aside "complacency" and builds on "guarded optimism," a process of "thinking first and organizing afterwards."

What has happened in academic libraries over the past twenty years in response to the alarms raised and the imperatives demanded by the authors of "Choosing Our Futures"? We are still debating issues of relevance and persistence for the future academic library. Note the recent Strategic Thinking and Design process carried out by ARL with the goal of defining and supporting emergent roles for research libraries. ${ }^{5}$ Mark the recent discussion in Inside Higher Ed exploring alternative visions for the future of liberal arts college libraries. ${ }^{6}$

Over the past twenty years, we have clearly encompassed and espoused technological change in the academic library, often serving as the locus of early adoption on our campuses. We have built the digital library, recognizing that quality clearly is defined as content plus functionality. Multimedia, integrated services, and software tools are central to our digital futures. We are generally failing in the persistence, curation, and stewardship of our converted, published and born-digital resources, and this threatens the quality and integrity of future scholarship.

We have the advantage of twenty years of perspective on the development and pervasive impact of academic technologies. When does quantitative change translate into qualitative change? I would cite the following: mobile and adaptable technologies, accessibility and support for print-disabled, the explosion in independent and self-publishing output, human/computer interaction and the importance of gaming and visualization, open-source software and hardware, network performance and security, repository chaos and the multiple places research is deposited and archived, metadata chaos and the issues of quality and currency, library as publisher, library and digital scholarship, open and mass learning, maker and digital fabricated spaces, researcher information systems, and so on. The accumulation of technological advances and opportunities explain and dictate change. The authors of "Choosing Our Futures" had the foresight to predict the impact of technology on organizational, staffing and resource priorities.

Clearly, we must achieve a deeper and actionable understanding of the diverse user community being served, and advance programs and interactions that respond to their expectations, enhance their experiences, and support their academic and life objectives.

Students want technology and content ubiquity, network access anywhere and anytime. They want web-based services, with no lines and no limits on hours. They want technology sandboxes, places for experimentation and fun, but also privacy spaces, places with protection and anonymity. They want support services, help when needed at appropriate levels of expertise, and guidance on advancing information fluency as a lifelong skill. And students want postgraduate access, not willing to leave behind the rich information content environments they enjoyed at the university.

We need to listen to our researchers as they tell us what support they are seeking from the academic library: the ability to navigate, analyze, and synthesize information; assistance with open research and the deformalism and destructuring of scholarly communication; guidance on moving from scholarly products to scholarly process and conversation; the development of expertise databases and subject ontologies; data management consulting; help with the integration of disparate and grey literatures. This demands a more special library and informationist model of academic library service.

Ultimately, the academic library needs to be passionately focused on user expectations and user loyalty. Users want more and better content, more and better access, 
convenience, new capabilities, ability to manage costs, participation and control, and individual and organizational productivity. The ability to satisfy and advance these requirements will define library success. We must implement more rigorous strategies for measuring and evaluating user satisfaction, market penetration, success, impact, cost effectiveness, and usability. This requires quantitative and qualitative measures that tell us if we are advancing institutional goals, supporting user objectives, and serving national interests. Our colleges and universities, and the governments that fund us, have raised expectations and mandates.

The authors of "Choosing Our Future" cite but do not address the economic context: smaller budgets, reduced purchasing power, declining political support, and enhanced competition for resources. Academic library staff must develop new sources of revenue, pursue entrepreneurial and R\&D capacities, and advance refreshed marketing strategies. Operating budget reallocation is not the only strategy. Equally important are fundraising, foundation and federal grants, co-investment with campus units, public/private partnerships, technology transfer, and new business development-all viable options.

We face the human resource and staffing challenges that encourage us to build new strategies for professional preparation, advancement and leadership. There are several human resource issues for the 21st-century academic library which, in my view, are critically linked to organizational and professional vitality. Academic libraries must articulate a broadly understood and accepted vision of librarianship, a new professional paradigm that incorporates strategic perspectives and qualities. A viable work force plan has not been developed for academic librarianship, defining and projecting personnel requirements both in terms of quantity and quality. The library education programs are not graduating librarians with the requisite skills to provide the essential leadership in the electronic community, librarians critical of current structures, service programs, or even the information value systems. Academic libraries are not responding effectively to the demographic shifts that are expanding cultural, racial, and ethnic diversity. Libraries have not viewed staff development as an integral and essential component of organizational success, with continuing education programs based on rigorous analysis of needs, recognized and well supported in budget planning, and mandated for all employee groups.

Academic libraries now hire an increasing number of individuals to fill professional librarian positions who do not have the master's degrees in library science. Instead of appointing librarians with the traditional qualifying credentials, they hire staff to fill librarian positions who hold a variety of qualifications, such as advanced degrees in subject disciplines, specialized language skills, teaching experience, or technology expertise. Academic libraries are also creating a wide range of new professional assignments in such areas as systems, human resources, fundraising, publishing, instructional technology, facilities management, and other specialties that demand diverse educational backgrounds.

The implications of these trends for the academic library work force and for the condition of the academic library workplace need close study. Historically, the shared graduate educational experience has provided a standard preparation and socialization into the library profession. The new professional groups have been "raised" in other environments and bring to the academic library a "feral" set of values, outlooks, styles, and expectations. We are only beginning to see the impact of these staffing strategies in such areas as employee relations, training, management, and leadership.

We must dismantle traditional organizational structures to create more agile advancement and more robust internal and external communications and collaborations. The basis of any organization is individuals and groups carrying out roles and working together to achieve shared objectives within a formal structure and with set 
processes. Organizations define the systems through which goals and priorities are established, decisions are made, resources are allocated, power is wielded, and plans are accomplished. They determine the degree to which administrative responsibility and authority are distributed and shared, operations and procedures are integrated and flexible, and policies and standards are designed and enforced.

Organizational models focus on a set of parameters defined by: centralization and decentralization, hierarchy and adhocracy, bureaucracy and distribution, simplicity and complexity, formality and informality, administration and entrepreneurship, authority and collaboration. They can be viewed, among many characteristics, in terms of layers and rigidity of structure, direction and effectiveness of information flow, sources and impact of leadership, participation in decision making, freedom of action, and levels of ambiguity.

Libraries have struggled to distribute authority, integrate key operations, break down bureaucratic processes, achieve less rigidity in structure, promote more cooperation across units, and build more matrix-type approaches to the work. As a result, centralized planning and resource allocation systems continue to coexist with broadly distributed and loosely coupled structures and an expanding array of maverick units like research centers and entrepreneurial enterprises.

We must build on the tradition of rich collaboration and implement new approaches to cooperation and systemic national strategies. Cooperation is part of the professional DNA of academic libraries. From the conditions of knowledge scarcity over the centuries to the oppression of information and data overabundance in today's and tomorrow's library context, cooperation has been and will be a constant for service, success, and survival. The definition and view of the academic library as an independent and self-sustaining organization, collaborating and sharing resources on the margin, has persisted. The future health of the library will be increasingly defined by new and energetic relationships and combinations, as well as the radicalization of working relationships among libraries, between libraries and the communities they serve, and in new entrepreneurial partnerships.

Radical collaboration encourages academic libraries to move in four new directions. The first is mass production, including (for example) backroom operations like acquisitions, cataloging, electronic resource management, and preservation that might be based in regional distribution centers rather than in every individual library. The second is centers of excellence, deep and shared polycentric strategies for specialized expertise or services. The third is new infrastructure, building the technologies and functionalities for areas like digital ingestion, processing, and archiving. The fourth is new initiatives, new programs and projects based on shared investment in experimentation. In all four cases, the measures of success must be quality, productivity, and innovation. Are we producing something new, saving resources, and achieving something better together than working alone? Radical collaboration requires bi- and trilateral collaborations, as well as multilateral approaches. They involve a business and sustainability plan, a legal framework and governance structure, risk capital to get it started, and a shared competitive spirit. And they must bring together libraries of similar visions and roles, whether research libraries or liberal arts college libraries.

Our planning processes are generally not supportive of the call for "Choosing Our Futures" that still rings valid today and tomorrow. There is too much strategic planning and not enough strategic thinking and action. Our existing structures and processes in higher education are built for a slower pace of change. Our academic library program planning is too often not linked to institutional planning. Our planning cycles are expenditure-based rather than strategic. Resource allocations are not linked to strategies. 
I have done extensive thinking recently about the historical and future development of the academic library. From what I call "the period of exclusivity" up to 1950, to the "period of popularization" or massive growth during 1950-1970, to the "period of discord" during 1970-1990, to the "period of decadence" during 1990-2010, when digital content and functionality exploded, libraries have experienced a roller-coaster ride of motivating highs and depressing lows. We are now in the time that I refer to as the "period of polygamy or Kumbaya," of massive and innovative collaborations and systemic national strategies, moving to a "period of parabiosis or synergy," of deep and sustained integration, to the "period of particularism," that is complementary specialization and interdependence.

Since the 1990s, when "Choosing Our Futures" was written, I would maintain that anxiety has accelerated and there is a heightened sense of urgency. The academic library is experiencing provocative disruption and disorder, and there is a fresh unpredictability in the complex systems that underpin the academic library. Can we rally primal innovation? Can we create sweeping and energetic combinations? Can we deconstruct, taking apart traditional axioms and norms, removing the incoherence of current concepts and models, and evolving new approaches and styles? Can we respond to the "human" objectives of our users, that is success, productivity, progress, relationships, experiences, and impact?

"Choosing Our Futures" is a provocative "think piece," translating thoughtful reflection about local practice into a series of observations and thoughts about the future of academic libraries. Does this sort of writing still have a place in College and Research Libraries? Yes, as we must deliberate our past, document and analyze our present, and debate our prospects and evolution.

\section{Notes}

1. James Elliot Cabot, A Memoir of Ralph Waldo Emerson, vol. 2 (Boston: Houghton, Mifflin and Company, 1887), 433.

2. Kahlil Gibran, The Vision: Reflections on the Way of the Soul (Ashland, Ore.: White Cloud Press, 1994), 64.

3. Susan Lee, Bonnie Juergens, and Richard Hume Werking, “Commentaries on 'Choosing our Futures," College \& Research Libraries 57, no. 3 (1996): 226-33, available online at http://crl.acrl. org/content/57/3/226.full.pdf+html [accessed 17 December 2014].

4. Thomas Kuhn, The Structure of Scientific Revolutions (Chicago: University of Chicago Press, 1962), 84 .

5. "ARL Strategic Thinking and Design," Association of Research Libraries, available online at www.arl.org/about/arl-strategic-thinking-and-design [accessed 15 December 2014].

6. Carl Straumsheim, "Clash in the Stacks," Inside Higher Ed, available online at www. insidehighered.com/news/2014/12/10/rethinking-library-proves-divisive-topic-many-liberal-artsinstitutions [accessed 15 December 2014]. 